\title{
Choice of therapeutic interventions and outcomes for the treatment of infections caused by multidrug-resistant gram- negative pathogens: a systematic review
}

Sarah Melissa Nørgaard ${ }^{1 \dagger}$, Camilla Skaarup Jensen ${ }^{1 \dagger}$, Josefine Aalestrup ${ }^{1 \dagger}$, Christina M. J. E. Vandenbroucke-Grauls ${ }^{3}$, Mark G. J. de Boer ${ }^{2}$ and Alma Becic Pedersen ${ }^{1 *}$ (i)

\begin{abstract}
Background: Antimicrobial resistance is an increasingly serious threat to public health, and the increased occurrence of multidrug-resistant (MDR) bacteria is a concern in both high-income and low- and middle-income countries. The purpose of this systematic review was to identify and critically appraise current antimicrobial treatment options for infections with MDR Gram-negative bacteria.

Methods: A literature search for treatment of MDR extended-spectrum beta-lactamase (ESBL)-producing Enterobacteriaceae, A. baumannii, and P. aeruginosa was conducted in MEDLINE in January 2019. Relevant studies published in English, German, and French that evaluated clinical success, microbiological success, and 30-day mortality outcomes were included. The population of interest was adult patients.

Results: Of 672 studies, 43 met the inclusion criteria. Carbapenems are the most common antibiotics used for the treatment of ESBL-producing Enterobacteriaceae. The clinical and microbiological success was similar for group 1 carbapenems (imipenem, meropenem, or doripenem), group 2 carbapenems (ertapenem), and non-carbapenem antibiotics. Mortality data were contradictory for group 1 carbapenems compared to group 2 carbapenems. The most common treatment option for $A$. baumannii and $P$. aeruginosa infections was intravenous colistin, regardless of infection site. Clinical success and mortality were similar in $A$. baumannii infections treated with colistin combination therapy vs. colistin monotherapy, whereas heterogeneous results were found with respect to microbiological success. Monotherapy and colistin combination therapy were used against $P$. aeruginosa with clinical and microbiological success (70-100\%) depending on the infection site and severity, and the antibiotic used. Ceftazidime-avibactam therapy for ESBL-producing Enterobacteriaceae and P. aeruginosa showed good clinical success in one study.

Conclusion: We did not find robust evidence for antibiotic treatment of any infection with MDR Gram-negative bacteria, including ESBL-producing Enterobacteriaceae, A. baumannii, and P. aeruginosa, that would lead to a firm recommendation for one specific antibiotic over another or for monotherapy over combination therapy. The choice of antibiotic treatment should be based on susceptibility testing balancing the expected clinical success rate against the risk of development of antibiotic resistance and the risk of severe side effects.
\end{abstract}

Keywords: A. baumannii, Enterobacteriaceae, MDR bacteria, P. aeruginosa, Review, Treatment

\footnotetext{
*Correspondence: abp@clin.au.dk

†'Sarah Melissa Nørgaard, Camilla Skaarup Jensen and Josefine Aalestrup contributed equally to this work.

'Department of Clinical Epidemiology, Aarhus University Hospital, Olof

Palmes Allé 43-45, 8200 Aarhus, N, Denmark

Full list of author information is available at the end of the article
}

(c) The Author(s). 2019 Open Access This article is distributed under the terms of the Creative Commons Attribution 4.0 International License (http://creativecommons.org/licenses/by/4.0/), which permits unrestricted use, distribution, and reproduction in any medium, provided you give appropriate credit to the original author(s) and the source, provide a link to the Creative Commons license, and indicate if changes were made. The Creative Commons Public Domain Dedication waiver (http://creativecommons.org/publicdomain/zero/1.0/) applies to the data made available in this article, unless otherwise stated. 


\section{Background}

Multidrug-resistant (MDR) infections constitute a serious public health problem [1] because they are difficult to treat effectively, leading to longer hospital stays, treatment failure, and adverse outcomes, such as complications and death $[2,3]$. During the last few decades, several bacterial pathogens have evolved into MDR forms [1, 4]; of particular concern are MDR Gram-negative pathogens, such as Enterobacteriaceae, Acinetobacter spp., and Pseudomonas aeruginosa [5], which are becoming resistant to almost all available antibiotics [6]. Extended-spectrum beta-lactamase (ESBL)-producing Enterobacteriaceae are responsible for a variety of community-onset and healthcare-associated infections and are associated with poor clinical outcomes [7, 8]. Acinetobacter baumannii can cause a variety of infections, including pneumonia and bloodstream infections, which are associated with high mortality and morbidity [9, 10]. $P$. aeruginosa is one of the main causes of serious nosocomial infections in Europe, including pneumonia, bloodstream infections, and urinary tract infections [11]. Other MDR Gram-negative bacteria are emerging, but are still rare and not a focus of the current review.

The European Centre for Disease Prevention and Control estimated in 2019 that infections caused by a subset of resistant bacteria are responsible for approximately 33,000 deaths in Europe annually [12]. The overall crude economic burden of antibiotic resistance in Europe has been estimated to be at least 900 million Euro in health care costs and 600 million Euros a year in lost productivity $[4,13]$. Despite the increased occurrence of MDR organisms, data on which antimicrobial treatment with a single antibiotic or a combination of two or more are scarce [14]. The available guidelines from the USA and Australia are based on data up to 2015, which may already be obsolete because of the expanding evolution of MDR Gram-negative bacteria. European guidelines mostly focus on preventative measures thought to reduce the occurrence of MDR Gram-negative bacteria [5, 15-20]. Previous systematic reviews were based on heterogeneous studies with small, diverse populations from single centers, comparing various antimicrobial treatment options, and providing different results.

The aim of this systematic review was to evaluate how different antimicrobial treatments used in adult patients against MDR infections, focusing on ESBL-producing Enterobacteriaceae, A. baumannii, and P. aeruginosa, affect clinical success and mortality outcomes.

\section{Methods}

The review protocol was not registered with the international prospective register of systematic reviews.

\section{Eligibility criteria}

Eligible study designs included randomized clinical trials, observational studies, prospective or retrospective design, concomitant or historical control studies, meta-analyses, and systematic reviews. Studies investigating any antimicrobial treatment for infections caused by MDR Gramnegative bacteria (ESBL-producing Enterobacteriaceae, $A$. baumannii, and P. aeruginosa) were included.

The population of interest was adult patients (age 18 years or older) who had a confirmed MDR infection and received antimicrobial treatment. We included studies that evaluated the outcomes of specific MDR Gramnegative bacteria with regard to the administered antimicrobial treatment. Studies directly comparing outcomes following different antibiotic treatments were of particular interest. However, we also included studies reporting the outcomes of specific treatments without a comparison treatment group.

The primary outcome of interest was clinical success from initiation of treatment until discharge or death. Clinical success was defined as complete resolution or substantial improvement of the signs and symptoms of the index infection, such that no further antibacterial therapy was necessary. Secondary outcomes were mortality, regardless of follow-up time after infection, or initiation of treatment and microbiological success measured by microbiological response, suppression, or eradication, bacteriological count, and laboratory outcome.

Studies published between January 1, 2006, and January 18, 2019, were included. For further details, please see the PICOS table (Additional file 1).

\section{Information source}

MEDLINE was searched via the PubMed electronic database under the guidance of a research librarian for articles, and the reference lists of the included articles were reviewed to find additional articles.

\section{Literature search}

Our search strategy included the following search terms: "multidrug resistant" AND "gram negative bacteria" AND "ESBL" OR “A. baumannii" OR " $P$. aeruginosa" (Additional file 2). We limited our search to the English, German, and French languages and studies in adult patients ( $\geq 18$ years). The search terms covered the title and abstract of the paper. We included studies with any method of diagnosing MDR infection and any antimicrobial treatment. Many definitions have been used to characterize MDR infection, and most articles were not clear about the definition. The European Committee on Antimicrobial Susceptibility Testing (EUCAST) defines MDR as acquired non-susceptibility to at least one agent in three or more antimicrobial categories [21]. If the authors classified infection as MDR, then the article was eligible for review, as we can only assume the EUCAST definition was applied. Any site of infection was included, including the respiratory tract, bloodstream, and 
urinary tract. Studies were selected through a threestage selection process described below. Additional articles were identified by checking the references of the already selected papers.

\section{Study selection}

Our initial search targeted articles that 1) evaluated infections with MDR ESBL Enterobacteriaceae, A. baumannii, or $P$. aeruginosa, 2) mentioned a potential antimicrobial treatment, and 3) included information on the outcome of treatment. First, a literature search was performed independently by three reviewing authors (SMN, CSJ, and JA), selecting relevant papers with the aforementioned MDR Gram-negative bacteria included in the title. Second, abstracts were reviewed by three reviewing authors for the other two eligibility criteria (administered antimicrobial treatment and outcome of interest). Due to different nomenclature for MDR, after consulting with the senior tiebreaking author (ABP), we decided to include different synonyms (e.g., carbapenem resistance and extremely drug-resistant) in the study selection process to insure inclusion of all articles concerning MDR bacteria. At the third stage, the full-text versions of potentially eligible publications were obtained and distributed evenly between the three reviewing authors and examined in detail according to a predefined extraction form (Tables 1, 2 and 3). Standardized, pre-determined, study criteria were applied to all full-text documents.

At each stage, disagreements about the fulfilment of eligibility criteria were resolved by consensus or in consultation with the senior tie-breaking author. Search results were exported to EndNote V.X7.4 (Thomson Reuters, New York, New York, United States) and duplicates removed. The EndNote database with full-text articles is available upon request. The selection process is presented in Fig. 1.

\section{Data extraction and assessment of study quality}

Data were extracted using a structured and standardized form piloted in six studies (Tables 1, 2 and 3). Discrepancies were compared to the original data. Information was extracted on the following characteristics: author names, year of publication, country of origin, study design, study period, characteristics of the study population (size, age, inclusion criteria, and site of infection), follow-up time, antimicrobial treatment and administration, outcome evaluated, factors for which the analysis was adjusted, statistical analyses, and risk estimates with $p$ values. Each review author presented extracted data for discussion with the other two review authors. If a review author had any doubt regarding extracted data, the paper was reviewed by another review author and disagreements resolved by discussion between the two review authors or in consultation with the senior author.
Table 1 Choice of treatment and outcomes for ESBL-producing Enterobacteriaceae

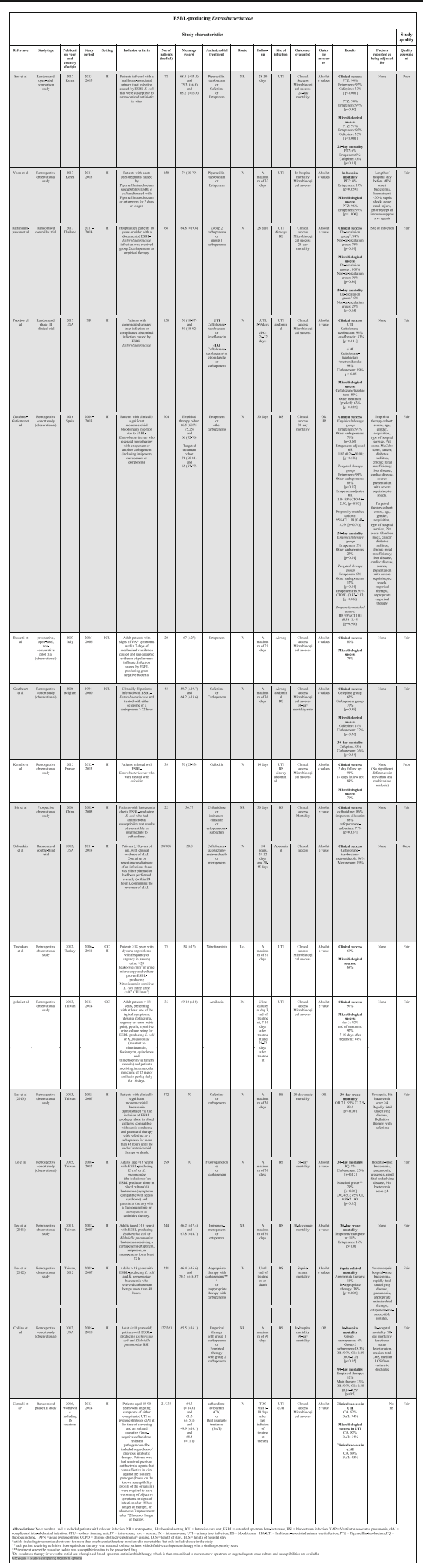


Table 2 Choice of treatment and outcomes for A. baumannii

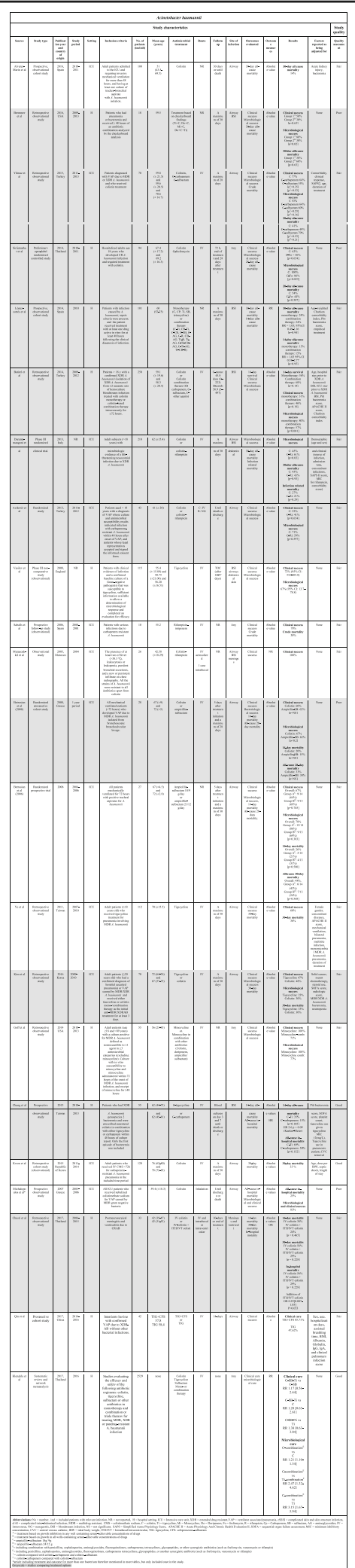

Quality and risk of bias in individual studies were assessed at the study and outcome level jointly by all reviewing authors using the Study Quality Assessment Tool from The National Heart, Lung, and Blood Institute [22]. The results of the quality assessment are presented in Tables 1, 2 and 3. Each study was quality rated according to one of the following categories based on the proportion of yes answers to all relevant questions: poor quality, 0-40\%; fair quality, $41-80 \%$; and good quality, $81-100 \%$ [22]. Quality assessments were conducted by the three authors jointly. Disagreements about the quality assessment were resolved by consensus or in consultation with the senior author.

\section{Summary measures}

The following measures of treatment success were included: absolute values, absolute risk differences, hazard ratio (HR), relative risk, and odds ratio. Unadjusted and adjusted measures were included if available.

\section{Planned methods of analyses}

The investigators considered quantifying effect measures in a weighted formal meta-analysis if there were consistency in the study designs, participants, antimicrobial treatment, and reported outcome measures. Otherwise, the systematic review would focus on describing the studies, their results, their applicability, and their limitations, and a qualitative synthesis of the results rather than a meta-analysis.

The systematic methodology of this review was based on the Preferred Reporting Items for Systematic Reviews and Meta-Analyses statement [23].

\section{Results}

Study selection

The literature search identified 672 studies. After an initial screening of the titles, 453 studies were excluded. Another 142 articles were excluded after reading the abstracts and 48 articles were excluded after reading the full-text because they did not meet the eligibility criteria. An additional 14 articles were included after identifying them from the reference lists of the already included papers. A total of 43 articles were included in the qualitative systematic review (Fig. 1).

\section{ESBL-producing Enterobacteriaceae}

We included 18 articles: 13 observational studies [24-36] and 5 randomized studies [37-41] (Table 1). Clinical success and mortality by antibiotics are presented in Figs. 2 and 3. Four studies compared treatment with group 1 carbapenems (ertapenem) to treatment with group 2 carbapenems (imipenem/meropenem) [25, 32, 36, 38]. No difference was found in clinical and microbiological success [38], but conflicting results were reported for mortality [32, 36, 38]. 
Table 3 Choice of treatment and outcome for Pseudomonas aeruginosa

\begin{tabular}{|c|c|c|c|c|c|c|c|c|c|c|c|c|c|c|c|c|}
\hline \multicolumn{17}{|c|}{ Pseudomonas aeruginosa } \\
\hline \multicolumn{16}{|c|}{ Study characteristics } & \multirow{2}{*}{$\begin{array}{c}\begin{array}{c}\text { Study } \\
\text { quality }\end{array} \\
\begin{array}{c}\text { Quality } \\
\text { assessment }\end{array}\end{array}$} \\
\hline Source & \begin{tabular}{|l|} 
Study type \\
\end{tabular} & \begin{tabular}{|c|c|} 
Publication \\
year and \\
countrof of \\
origin \\
oris
\end{tabular} & \begin{tabular}{|c|c} 
Study \\
period
\end{tabular} \mid & Setting & Inclusion criteria & \begin{tabular}{|c|}
$\begin{array}{c}\text { No of } \\
\text { patients } \\
\text { (inclalli) }\end{array}$ \\
\end{tabular} & $\begin{array}{c}\text { Mean } \\
\text { age } \\
\text { (years) }\end{array}$ & $\begin{array}{c}\text { Antimicrobial } \\
\text { treatment }\end{array}$ & Route & \begin{tabular}{|l|} 
Follow- \\
up
\end{tabular} & \begin{tabular}{|l|}
$\begin{array}{c}\text { Site of } \\
\text { infection }\end{array}$ \\
intion
\end{tabular} & $\begin{array}{l}\text { Outcomes } \\
\text { evaluated }\end{array}$ & $\begin{array}{l}\text { Outcome } \\
\text { measures }\end{array}$ & Results & $\begin{array}{l}\text { Factors reported } \\
\text { as bing } \\
\text { adjusted for }\end{array}$ & \\
\hline Sorti et al & \begin{tabular}{|l|}
$\begin{array}{l}\text { Prospective } \\
\text { observational } \\
\text { cohort sudy }\end{array}$ \\
\end{tabular} & 2017, Spain & \begin{tabular}{|l|}
$2009-$ \\
2013
\end{tabular} & $\mathrm{H}$ & 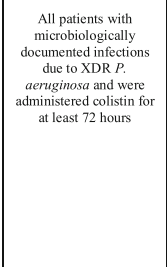 & 91 & \begin{tabular}{c|} 
Age \\
range: \\
$24-88$
\end{tabular} & Colistin & IV & \begin{tabular}{|l|}
$\begin{array}{c}\text { Until } \\
\text { discharge } \\
\text { or death }\end{array}$ \\
\end{tabular} & Any & \begin{tabular}{|l} 
Clinical success \\
30-dyy all- \\
cause mortality
\end{tabular} & $\begin{array}{c}\text { Absolute } \\
\text { value }\end{array}$ & $\begin{array}{c}\text { Clinical success } \\
79 \% \\
\text { 30-day all-cause } \\
\text { mortality } \\
31 \%\end{array}$ & 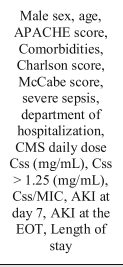 & Fair \\
\hline Wrightet al & 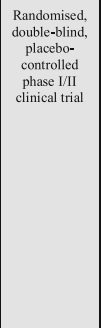 & $\begin{array}{c}2009, \\
\text { United } \\
\text { Kingdom }\end{array}$ & NR & oc & $\begin{array}{l}\text { Longstanding, antibiotic } \\
\text { resistant, aurara dischargec } \\
\text { due to infection } \\
\text { exclusivively or } \\
\text { predominantly by } P . \\
\text { aeruginosa. }\end{array}$ & 24 & 56.7 & $\begin{array}{c}\text { Biophage-PA } \\
\text { lac } \\
\text { placebo }\end{array}$ & \begin{tabular}{|l|l}
$\substack{\text { Injection } \\
\text { into onc } \\
\text { ear }}$ \\
ear
\end{tabular} & $\begin{array}{c}\text { Day } 7, \\
21 \text { and } \\
42\end{array}$ & Ear & \begin{tabular}{|c} 
Physician \\
reported VAS \\
Patient reported \\
VAS \\
Pseudomonas \\
count
\end{tabular} & $\begin{array}{c}\text { Mean } \\
\text { reduction } \\
\text { percentage } \\
\text { of day } 0\end{array}$ & 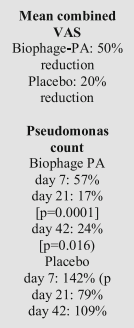 & None & Fair \\
\hline Montero et al & \begin{tabular}{|l|l} 
Retrospective \\
observational \\
sududy
\end{tabular} & 2009, Spain & \begin{tabular}{|l|}
$1997-$ \\
2006
\end{tabular} & $\mathrm{H}$ & \begin{tabular}{|c|} 
Patients who received \\
treatment with colisinn \\
for more than 3 days \\
following an episode of \\
active infection with \\
MDR $P$. aeruginosa
\end{tabular} & 121 & $\begin{array}{l}65.34 \\
( \pm 14.1)\end{array}$ & $\begin{array}{c}\text { Colistin } \\
\text { of } \\
\text { colsisin } \\
\text { associated with } \\
\text { aminoglycosides, } \\
\text { p-lactans, } \\
\text { quinolones or } \\
\text { carbapenems }\end{array}$ & \begin{tabular}{|l|l} 
IV and \\
IV+Nb
\end{tabular} & $\mathrm{NR}$ & Any & Clinical success & $\begin{array}{c}\text { Absolute } \\
\text { value }\end{array}$ & 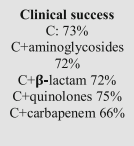 & $\begin{array}{l}\text { Site of infection, } \\
\text { hypertension, } \\
\text { chronic renal } \\
\text { insurficiency, } \\
\text { diabetes mellitus, } \\
\text { Aminoglycosides, } \\
\text { AEE-inibititors }\end{array}$ & Poor \\
\hline$\underset{\substack{\text { Carmeli et } \\
\mathrm{a}^{*}}}{\text { a }}$ & \begin{tabular}{|l} 
Randomized \\
phas cIII \\
study
\end{tabular} & 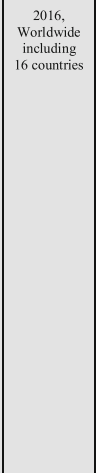 & \begin{tabular}{|l|}
$2013-$ \\
2014
\end{tabular} & H & 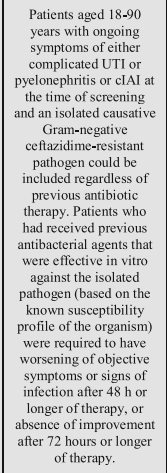 & $21 / 333$ & $\begin{array}{c}64.3 \\
(+1.9 \\
\text { and } \\
61.3 \\
( \pm 11.3) \\
\text { and } \\
49.9 \\
( \pm 1.1) \\
\text { and } \\
68.4 \\
( \pm 11.1)\end{array}$ & $\begin{array}{c}\mathrm{CA} \\
\text { or } \\
\mathrm{BAT}\end{array}$ & IV & \begin{tabular}{|c|} 
Toc \\
visit 7 -10 \\
dalys \\
aft last \\
infusion \\
of \\
treatment \\
therapy
\end{tabular} & $\begin{array}{l}\text { UTI } \\
\text { cIAI }\end{array}$ & \begin{tabular}{|c|c} 
Clinical success \\
Micreboidogical \\
success
\end{tabular} & $\begin{array}{c}\text { Absolute } \\
\text { value }\end{array}$ & 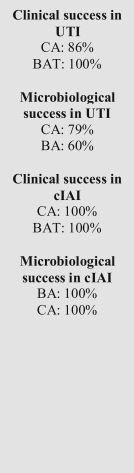 & None & Fair \\
\hline $\begin{array}{l}\text { Abbreviat } \\
\text { TOC = test } \\
\text { inhibitity } \\
\text { tarticle in } \\
\text { Greyscale }\end{array}$ & $\begin{array}{l}\mathrm{II}=\text { uri } \\
\text { ni } \mathrm{AKI}\end{array}$ & $\begin{array}{l}\text { clculec } \\
\text { fectio } \\
\text { ndey }\end{array}$ & & & dominal infection, & . & 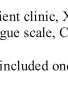 & tin, AP, & & & & Evaluata & col & e sodi & tready & $\begin{array}{l}\text { orted, } \\
\text { minimal } \\
\text { the }\end{array}$ \\
\hline
\end{tabular}

Lee et al. reported a lower sepsis-related mortality among 251 patients receiving appropriate therapy (11\%) compared to those receiving inappropriate therapy (38\%) regardless of whether it was ertapenem, imipenem, or meropenem [33]. Bassetti et al. showed that treating ventilator-associated pneumonia with ertapenem had more than $75 \%$ clinical and microbiological success [42]. No difference was found in 30-day mortality for treatment with fluoroquinolones compared to carbapenems, whereas patients treated with cefepime were more likely to die within 30 days than patients treated with carbapenems [34]. A single study [24] found no difference between ertapenem and piperacillintazobactam in mortality or microbiological success for patients with acute pyelonephritis.

Goetheart et al. compared imipenem/meropenem as monotherapy or in combination with other antibiotic treatment options to treatment with cefepime [27]. Patients treated with cefepime and imipenem/meropenem had similar clinical and microbiological success and 30day mortality. Solomkin et al. found no difference in clinical success between ceftolozane/tazobactam+metronidazole and meropenem treatment [40]. Carmeli et al. 


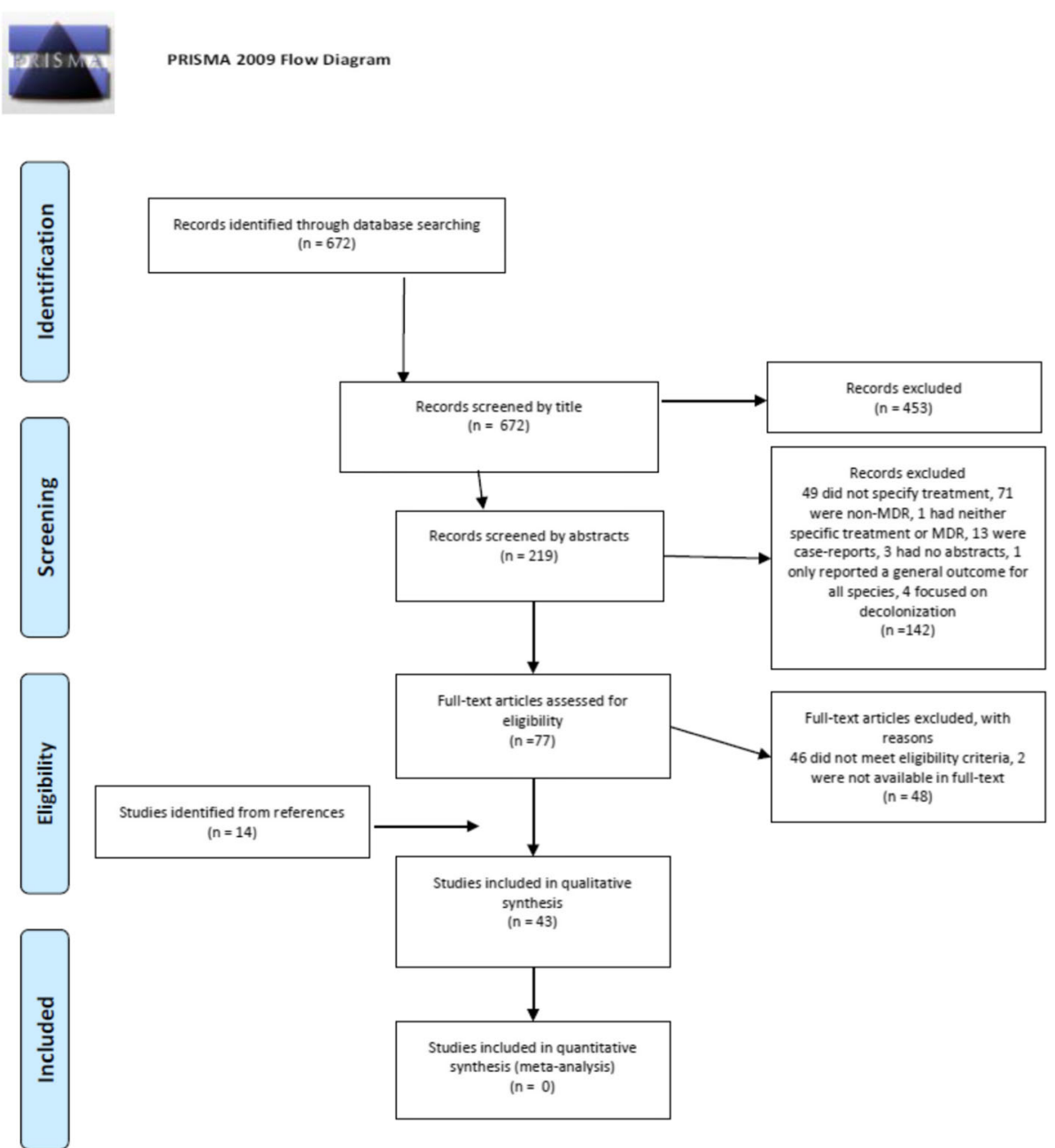

Fig. 1 PRISMA flow diagram

investigated ceftazidime-avibactam against group 2 carbapenem monotherapy (mostly imipenem and meropenem, but also other treatments) [41] in 263 patients with urinary tract infection and 20 patients with complicated intraabdominal infections (cIAIs) caused by ESBL-producing Enterobacteriaceae or $P$. aeruginosa. Clinical success was reported in more than $92 \%$ of patients with urinary tract infection caused by ESBL-producing Enterobacteriaceae treated with ceftazidime-avibactam and best available treatment (monotherapy with amikacin, colistin, doripenem, ertapenem, ertapenem sodium, gentamicin, imipenem, or meropenem piperacillin/tazobactam and combination therapy with ciprofloxacin + meropenem or colistin + imipenem), whereas microbiological success was achieved in $64 \%$ of patients treated with ceftazidime-avibactam compared to $82 \%$ treated with best available treatment. Clinical success was reported in 5 of 11 patients with cIAI due to ESBLproducing Enterobacteriaceae treated with ceftazidimeavibactam compared to 8 of 9 patients treated with the best available treatment.
Other treatment options included piperacillintazobactam vs. ertapenem vs. cefepime [37], ceftolozane/ tazobactam vs. levofloxacin and ceftolozane/tazobactam vs. ertapenem [39], and ceftazidime vs. imipenem/cilastatin vs. cefoperazone/sulbactam [29]. Seo et al. reported a difference in clinical success when treating 72 patients with urinary tract infection with piperacillin-tazobactam vs. ertapenem vs. cefepime ( $94 \%$ vs. $97 \%$ vs. $33 \%$ ), whereas microbiological success and 28-day mortality were similar [37]. A phase III clinical trial [39] investigated patients with urinary tract infection randomly assigned to treatment with ceftolozane-tazobactam or levofloxacin, and patients with cIAI randomly assigned to treatment with ceftolozanetazobactam or ertapenem. Better clinical success was noted when treating urinary tract infection with ceftolozane/tazobactam compared to levofloxacin (98 and 83\%). The clinical success in patients with cIAI was $96 \%$ for ceftolozane/ tazobactam and $89 \%$ for carbapenem. Bin et al. found similar clinical success when treating with ceftazidime imipenem/cilastatin and cefoperazone/sulbactam [29]. 


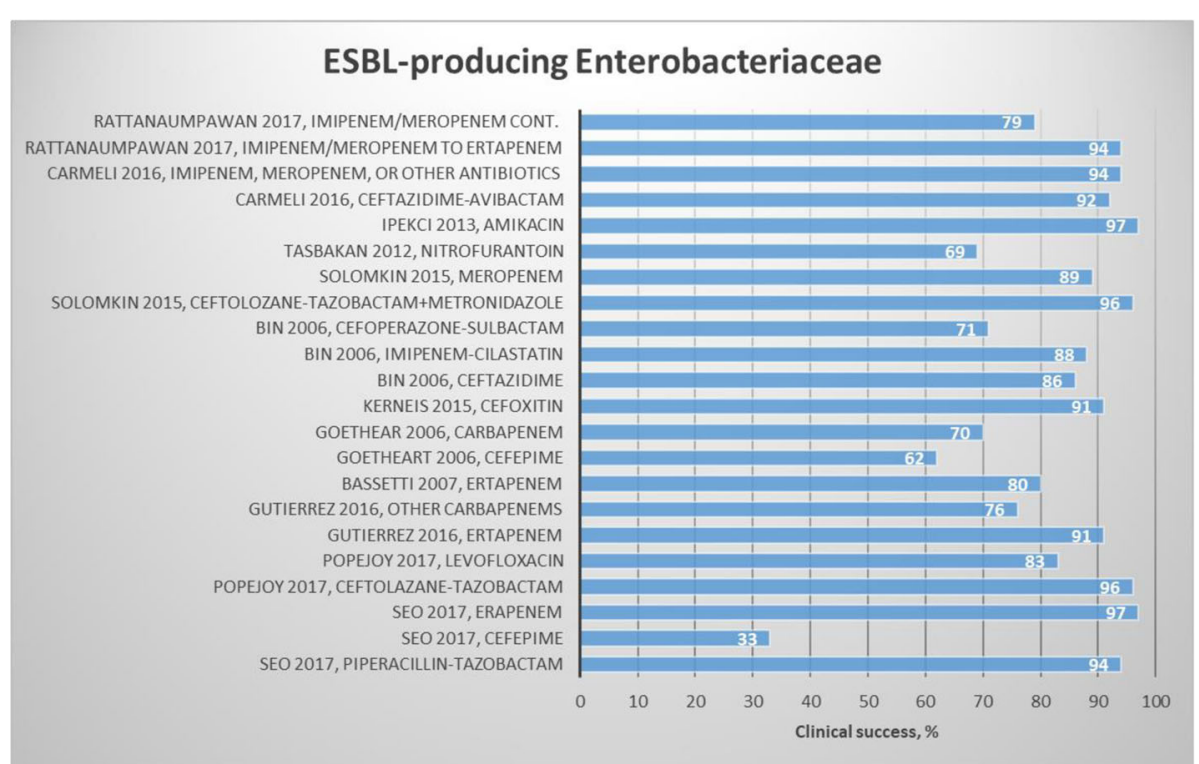

Fig. 2 Results regarding choice of treatment and clinical success for ESBL-producing Enterobacteriaceae

In conclusion, for ESBL-producing Enterobacteriaceae, treatment with carbapenems (ertapenem and meropenem) was associated with low sepsis-related mortality [33]. Seven studies found similar effects between a number of alternative treatment options and carbapenems regarding mortality $[24,27,35,37]$, clinical success [27, $40,41,43]$, and microbiological success [27, 43]. Regarding the clinical success, the following drugs alone or in combination had a success rate $>90 \%$ : piperacillintazobactam, ceftolazane-tazobactam, ertapenem, ertapenem, cefoxitin, ceftolozane-tazobactam in addition to metronidazole, amikacin, and cetazidime-avibactam. In addition, the following drugs had 80 to $90 \%$ clinical success: levofloxacin, ceftazidime, imipenem-cilastatin, and meropenem. Mortality was less than $10 \%$ for piperacillin-tazobactam and fluoroquinolones. However,

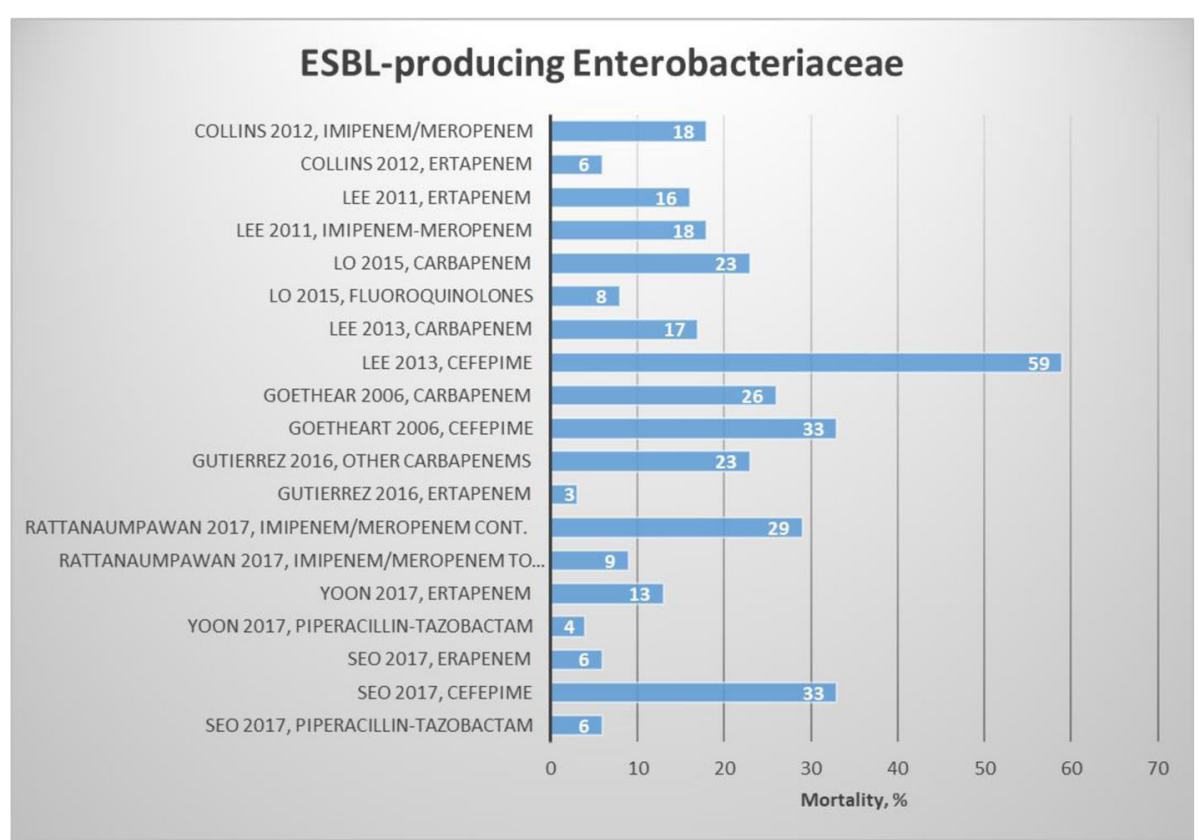

Fig. 3 Results regarding choice of treatment and mortality for ESBL-producing Enterobacteriaceae 
more than $10 \%$ mortality was observed for cefepime, imipenem/meropenem, and carbapenem. Conflicting results regarding mortality were observed for ertapenem.

\section{Acinetobacter baumannii}

We identified 22 studies, 16 of which were observational studies [44-59], five were randomized clinical trials [6064], and one was systematic review and meta-analysis [65] (Table 2). The studies were based on populations with different sites of infection (airways, bloodstream, abdomen, skin, and meninges) and study population size varying from 10 to 250 patients.

Four articles compared colistin monotherapy to colistin combination therapy. Yilmaz et al. reported $77 \%$ clinical success with colistin monotherapy compared to 64 and 55\% for colistin-carbapenem therapy and colistinsulbactam therapy, respectively [46]. Sirijatupha et al. reported 63\% clinical success with colistin monotherapy and $56 \%$ for colistin-fosfomycin combination therapy [60]. Batirel et al. reported a clinical success rate of $31 \%$ for monotherapy and $46 \%$ for colistin combination therapy (carbapenem, sulbactam, and other agents) [48]. Finally, Aydemir et al. reported 52\% clinical success with colistin monotherapy compared to $41 \%$ with colistinrifampicin [61].

Conflicting results have been reported regarding the microbiological success of colistin monotherapy compared to combination therapy with carbapenem or sulbactam. Two studies found no difference in microbiological success [46, 61], whereas Batirel et al. found that combination therapy for bloodstream infection had a better microbiological outcome than monotherapy [48]. Durante-Mangoni et al. found that microbiological success was more likely with colistin-rifampicin combination therapy than colistin monotherapy [64]. Systemic colistin and combinations with localized colistin have been shown to have similar effects on mortality [59].

Therapy with ampicillin-sulbactam was not superior to colistin monotherapy with regard to clinical success, 14day mortality, or 28-day all-cause mortality among patients with MDR A. baumannii ventilator-associated pneumonia [62]. Betrosian et al. found similar clinical success and 30-day mortality when comparing low and high doses of ampicillin-sulbactam among patients with ventilator-associated pneumonia, but microbiological success was better in the low dose group [63]. Colistinfosfomycin combination therapy had better microbiological success than colistin monotherapy, whereas 28day all-cause mortality was similar when MDR A. baumannii infection at various sites was treated [60]. Tigecycline therapy was not superior to colistin therapy in terms of microbiological and clinical success or 30-day mortality among critically ill patients with MDR A. baumannii pneumonia [52, 58]. In another study, combination therapy with colistin-tigecycline and colistin-carbapenem resulted in 14-day all-cause mortality of $35 \%$ vs. $15 \%$ and all-cause in-hospital mortality of $69 \%$ vs. $50 \%$, respectively [54]. Kengkla et al. reported similar clinical success when comparing different colistin combination therapies to different colistin monotherapies, but a better microbiological outcome was demonstrated with colistin combination therapy vs. colistin monotherapy, and tigecycline combination therapy vs. tigecycline monotherapy [65]. No difference was found in all-cause mortality between colistin combination therapy vs. sulbactam combination therapy [65]. Antibiotics other than colistin were evaluated in several small studies $[49-51,53,57]$.

In conclusion, for A. baumannii, colistin combination therapy had no clear advantage over colistin monotherapy in regards to clinical success [46, 48, 60, 61] (Fig. 4). However, conflicting results have been reported regarding microbiological success when evaluating colistin monotherapy and colistin in combination with carbapenem [46], sulbactam [48], or rifampicin [61, 64]. Therapy with colistin monotherapy did not have a better outcome than ampicillin/sulbactam [52], and no difference in mortality was reported for any treatment comparison. Furthermore, tigecycline and minocycline [49, $51,58]$ had a good effect on clinical and microbiological outcome, but the studies were small.

\section{Pseudomonas aeruginosa}

Four studies on $P$. aeruginosa were included in our review: two observational studies $[66,67]$ and two randomized controlled studies [41, 68] (Table 3). The largest study population comprised 263 patients. Clinical success rates are presented in Fig. 5.

Sorli et al. reported a clinical success rate of $79 \%$ after 30 -days and a 30 -day mortality of $31 \%$ for treatment with intravenous colistimethate sodium for $P$. aeruginosa infection at any site, except acute bronchitis and tracheitis [66]. Montero et al. reported similar clinical success for treatment with colistin monotherapy versus colistin combination therapy (aminoglycosides, $\beta$-lactams, quinolones, and carbapenems) in patients infected with $P$. aeruginosa at different infection sites [67]. Carmeli et al. compared ceftazidime-avibactam to the best available treatment (monotherapy with amikacin, colistin, doripenem, ertapenem, ertapenem sodium, gentamicin, imipenem, meropenem or piperacillin/tazobactam and combination therapy with ciprofloxacin + meropenem or colistin + imipenem) for patients with urinary tract infection or cIAI caused by MDR $P$. aeruginosa or ESBL-producing Enterobacteriaceae. Clinical and microbiological success occurred in 86 and $79 \%$ of patients with $P$. aeruginosa-specific urinary tract infection treated 


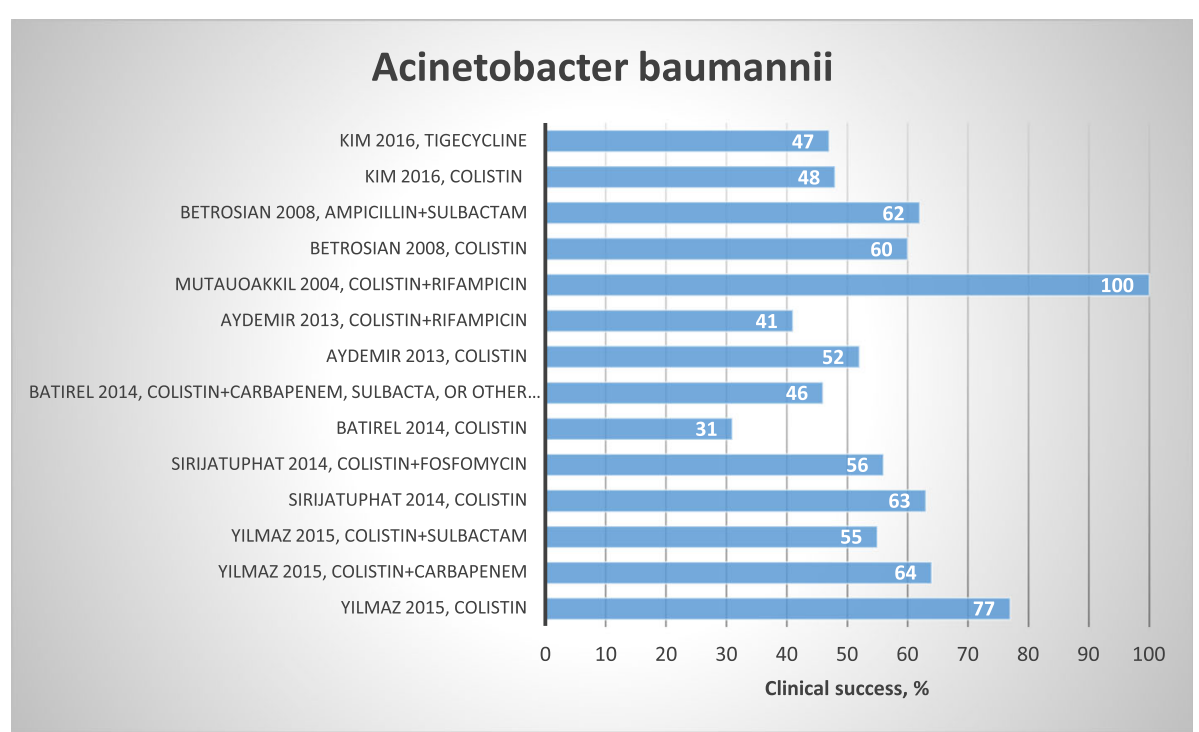

Fig. 4 Results regarding choice of treatment and clinical success for A. baumannii

with ceftazidime-avibactam and $100 \%$ of patients treated with the best available treatment [41].

In conclusion, for $P$. aeruginosa, evaluated studies were characterized by heterogeneous study design, site of infection, and treatment used. Clinical success between 70 and $100 \%$ was reported regardless of the type of antibiotic treatment (Fig. 5). A high clinical success rate of up to $100 \%$ for ceftazidime-avibactam was demonstrated in the randomized study of Carmeli et al., in which a number of exclusion criteria were applied (i.e., both patients with complicated urinary tract infection and intra-abdominal infection were excluded, as were patients with evidence of abnormal liver function). Due to small sample sizes and variability in the type of antibiotics used, it is not possible to recommend one specific antibiotic over another.

\section{Risk of Bias}

In general, the study quality varied, $16 \%(\mathrm{n}=7)$ of studies were poor in terms of quality, $74 \%(n=32)$ were fair, and only $9 \%(n=4)$ were good quality (Tables 1,2 and 3$)$.

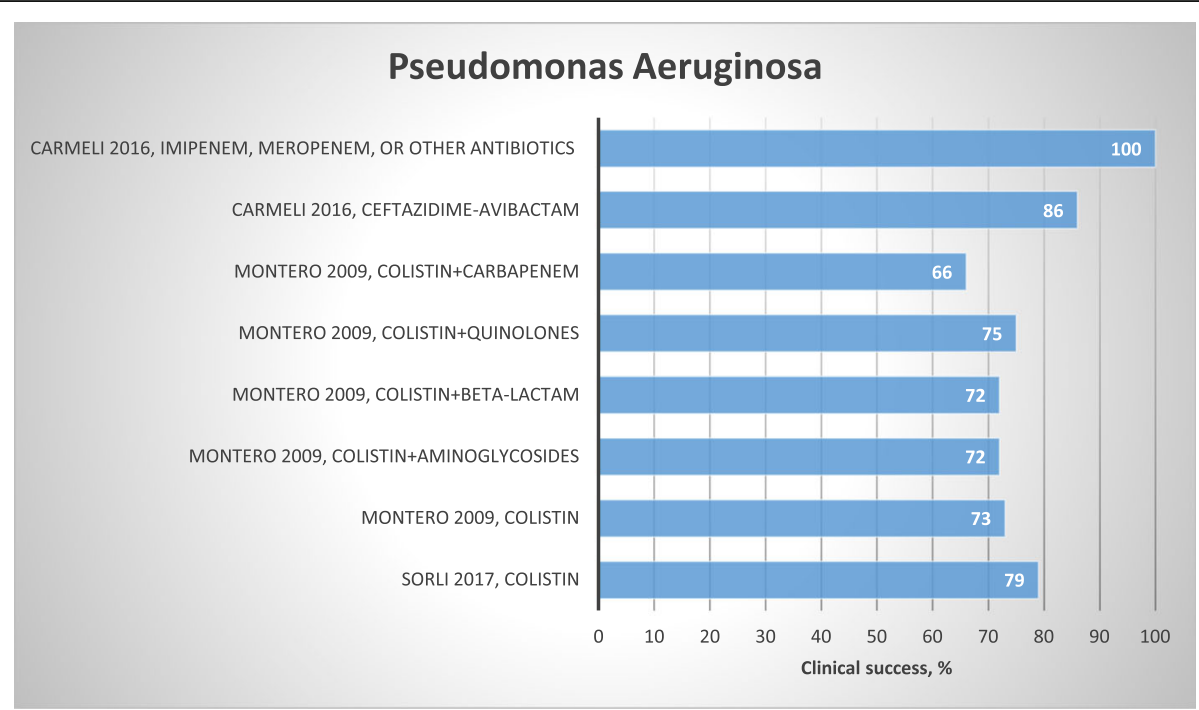

Fig. 5 Results regarding choice of treatment and clinical success for $P$. aeruginosa 


\section{Discussion}

In summary, we identified 43 articles that report on the clinical success, microbiological success, and/or mortality of different treatment options for the three most common MDR Gram-negative bacteria: ESBL-producing Enterobacteriaceae, A. baumannii, and P. aeruginosa. A variety of antimicrobial regimens have been used, but we did not find robust evidence that would lead to a firm recommendation of one specific antibiotic over another or for monotherapy over combination therapy with regard to efficacy in infections caused by these three different groups of MDR bacterial species. For the treatment of ESBLproducing Enterobacteriaceae, the most commonly used antibiotics were carbapenems. The effect of group 1 carbapenems (ertapenem) compared to group 2 carbapenems (imipenem, meropenem or doripenem) was heterogeneous with regard to reducing mortality, whereas the clinical and microbiological success were similar for group 1 and 2 carbapenems and other non-carbapenem antibiotics. Carbapenem should be used as a 'last-line' antibiotic, and other antibiotics should be used based on the antibiotic resistance profile. For treatment of MDR A. baumannii, intravenous colistin was used as the first drug of choice. Clinical success and mortality were similar in cases treated with colistin combination therapy or monotherapy, whereas heterogeneous results were found with regard to microbiological success. One study compared ampicillin/sulbactam to colistin monotherapy and found that patient groups had a similar outcome. The most common option for treatment of MDR $P$. aeruginosa infections was intravenous colistin, regardless of infection site.

Adverse reactions to the antibiotics were not a focus of this study but are an important aspect in the treatment of patients, as dosage adjustments must be considered and may have affected the results in this review in terms of clinical success, bacteriological success, and mortality. Another perspective is that patients infected with the studied bacteria are often critically ill, which makes it important to have extensive knowledge of the effects and side effects of the treatment of choice (e.g., the occurrence of nephrotoxicity due to colistin treatment makes colistin a less favorable choice than other antibiotics). Antimicrobial therapy can contribute to curation, but in many complicated infections, surgery and drainage procedures are essential. The included studies that reported multivariate analyses often emphasized the confounding effects of the severity of illness and patient comorbidity.

Ceftazidime-avibactam was introduced in the USA in 2015 and on the European market in 2016 for treatment of adults with complicated urinary tract infections, complicated intra-abdominal infections, hospital-acquired pneumonia, and other infections caused by Gramnegative organisms in patients with limited treatment options [69]. Current evidence of the effectiveness of ceftazidime-avibactam compared to treatment with carbapenem monotherapy in patients with ceftazidimeresistant Enterobacteriaceae and $P$. aeruginosa is good, and combinations could be considered to reduce the occurrence of carbapenem-resistant bacteria.

To the best of our knowledge, no other systematic reviews have resulted in specific guidelines for treatment of MDR Gram-negative infections. A prior systematic review suggested that colistin combination therapy may be preferred to colistin monotherapy for severely ill patients infected with MDR A. baumannii, but no firm evidence could be found [19]. Another systematic review proposed treating carbapenem-resistant ESBL-producing Enterobacteriaceae and $P$. aeruginosa with carbapenem plus either colistin or tigecycline combination therapy in low-level resistant infections and colistin-tigecycline combination therapy in high-level resistant infections [18]. Similar findings were published by Rafailidis et al. in 2014, concluding that carbapenem in combination with colistin or high-dose tigecycline or aminoglycosides could be used for treatment of carbapenem-resistant ESBL-producing Enterobacteriaceae in cases in which the minimum inhibitory concentration ranges of carbapenems are $\leq 8 \mathrm{mg} / \mathrm{L}$ [20].

The included studies were heterogeneous in terms of study design, patient population, site of infection, choice of antibiotic treatment, duration of follow-up, and outcome definitions, making it difficult to compare the different treatments and combinations of antibiotics used. Subsequently, we were not able to pool results for a meta-analysis. Most patients included in the studies were critically ill, with multiple comorbidities, and admitted to an intensive care unit; these factors may lead to underestimating the specific effect of a certain antibiotic treatment on mortality. Some studies included patients regardless of the site of infection, whereas other studies included patients with specific infections, such as pneumonia or urinary tract infection. The severity of these infections is different, which again can affect the antibiotic treatment-related outcome. In addition, the studies were often based on small sample sizes, reducing the ability to find any effect difference and to consider confounder adjustment and multivariate regression analysis. Only a few studies $[24,25,34,36,40,44,47,51,52,54$, $55,64]$ presented a sample size estimation and adhered to it.

Our study has several limitations. We only used the MEDLINE database for the literature search, which may not cover all published articles. We limited our search to the English, German, and French languages. As countries speaking other languages may have greater problems with MDR bacteria, we may have missed articles published in other languages. However, due to the major 
shift towards the publication of studies in English, the extent and effects of language bias may have decreased over the last few years. Lack of a standard definition of MDR results in a great diversity of published papers when defining MDR [70]. Consequently, the use of the term MDR in our search strategy may not cover the same bacteria and drug resistance, and we may have missed some relevant articles. In an attempt to avoid excluding relevant literature, different synonyms were accepted as MDR (e.g., carbapenem resistance and XDR) and all references in the included articles were screened for eligibility. Our inclusion criteria did not take susceptibility profile testing into consideration. Therefore, our results do not differentiate between studies with adequate and inadequate empiric treatment based on the susceptibility profile and studies in which treatment was targeted after the microbiological results were available. However, the vast majority of studies did not clearly state whether the susceptibility profile testing was done before the initiation of treatment. Risk of publication bias is another limitation of this review. It is possible that studies reporting on antibiotic treatment with high clinical and microbiological success rates are more likely to be published. Approximately $50 \%$ of the studies are estimated to be unpublished, including a majority of studies with less significant or negative results. Furthermore, $36 \%$ of the included studies were found by screening the reference lists of published articles, which may have caused notation bias.

\section{Conclusions}

A variety of antimicrobial therapies have been used for treatment of the three most common MDR Gramnegative bacteria: ESBL-producing Enterobacteriaceae, A. baumannii, and P. aeruginosa. Carbapenems, in many situations, may have similar clinical and microbiological success rates as other antimicrobial regimens when used for the treatment of infections caused by ESBLproducing Enterobacteriaceae. For treatment of MDR $A$. baumannii, clinical success and mortality were similar in cases treated with colistin combination therapy compared to monotherapy, as well as in several studies comparing colistin with other antibiotics. The most common choice for treatment of MDR $P$. aeruginosa infections was intravenous colistin, regardless of infection site. Other antibiotic therapies had a similar effect as colistin, but due to small sample sizes and variability in the type of antibiotics used, it is not possible to recommend one specific antimicrobial regimen over another. The choice of definite antibiotic treatment should be based on susceptibility testing balancing the expected clinical success rate against the risk of development of antibiotic resistance and the risk of severe side effects. Taking into account the absence of evidence and all considerations above, for now, a personalized medicine approach and involvement of specialists in infectious diseases and microbiology are key measures to provide optimal treatment for each patient affected by infection caused by MDR microorganisms.

\section{Supplementary information}

Supplementary information accompanies this paper at https://doi.org/10 1186/s13756-019-0624-1.

Additional file 1. PICOS criteria.

Additional file 2. Search criteria.

\section{Abbreviations}

CIAl: Complicated intra-abdominal infection; ESBL: Extended-spectrum betalactamase; HR: Hazard ratio; MDR: Multidrug-resistant

\section{Acknowledgements}

Not applicable

\section{Authors' contributions}

SMN, CSJ, and JA designed the work, acquired data, interpreted the data, drafted the work, modified and approved the submitted version, and are responsible for the manuscript. MB and CV interpreted data, substantively revised the work, approved the submitted version, and agreed to be personally accountable for the author's own contributions. ABP designed the work, interpreted data, substantively revised the work, approved the submitted version, is responsible for the manuscript, and agreed to be personally accountable for the author's own contributions.

\section{Funding}

The research received a specific grant from the European Medicines Agency (EMA) contract EMA/2015/24/PH. The EMA has commented on the review content but did not have a final decision on the interpretations or conclusions of the review.

\section{Availability of data and materials}

The datasets generated during the current study are available from the corresponding author upon reasonable request.

Ethics approval and consent to participate Not applicable

\section{Consent for publication}

Not applicable

\section{Competing interests}

The authors declare that they have no competing interests.

\section{Author details}

${ }^{1}$ Department of Clinical Epidemiology, Aarhus University Hospital, Olof Palmes Allé 43-45, 8200 Aarhus, N, Denmark. ²Department of Infectious Diseases, Leiden University Medical Center, Albinusdreef 2, 2333, ZA, Leiden, The Netherlands. ${ }^{3}$ Medical Microbiology and Infection Control, Amsterdam University Medical Centers, Vrije Universiteit, De Boelelaan 1117 Amsterdam, 1081, HV, Amsterdam, The Netherlands.

Received: 17 June 2019 Accepted: 9 October 2019

Published online: 04 November 2019

References

1. WHO. Antimicrobial resistance: global report on surveillance. 2015. Available on: https://apps.who.int/iris/bitstream/handle/10665/112642/978924156474 8_eng.pdf;jsessionid=6340DE5721019788DC15BBF4EAD4B8F6? sequence=1. Accessed 26 Oct 2019.

2. Giske CG, Monnet DL, Cars O, Carmeli Y. Clinical and economic impact of common multidrug-resistant gram-negative bacilli. Antimicrob Agents Chemother. 2008;52(3):813-21. 
3. Ventola CL. The antibiotic resistance crisis: part 1: causes and threats. P t. 2015;40(4):277-83.

4. Antimicrobial resistance surveillance in Europe Annual report of the European Antimicrobial Resistance Surveillance Network (EARS-Net) 2014. Stockholm: ECDC; 2015. Available on: https://www.ecdc.europa.eu/sites/ default/files/media/en/publications/Publications/antimicrobial-resistanceeurope-2014.pdf.

5. Taneja N, Kaur H. Insights into newer antimicrobial agents against gramnegative Bacteria. Microbiol Insights. 2016;9:9-19.

6. Rossolini GM, Arena F, Pecile P, Pollini S. Update on the antibiotic resistance crisis. Curr Opin Pharmacol. 2014;18:56-60.

7. Ramphal R, Ambrose PG. Extended-spectrum beta-lactamases and clinical outcomes: current data. Clin Infect Dis. 2006;42(Suppl 4):S164-72.

8. Chopra T, Marchaim D, Veltman J, Johnson P, Zhao JJ, Tansek R, Hatahet D, Chaudhry K, Pogue JM, Rahbar H, Chen TY, Truong T, Rodriguez V, Ellsworth J, Bernabela L, Bhargava A, Yousuf A, Alangaden G, Kaye KS. Impact of cefepime therapy on mortality among patients with bloodstream infections caused by extended-spectrum-beta-lactamase-producing Klebsiella pneumoniae and Escherichia coli. Antimicrob Agents Chemother. 2012; 56(7):3936-42.

9. Dijkshoorn $\mathrm{L}$, Nemec A, Seifert $\mathrm{H}$. An increasing threat in hospitals: multidrug-resistant Acinetobacter baumannii. Nat Rev Microbiol. 2007; 5(12):939-51.

10. Li J, Nation RL, Turnidge JD, Milne RW, Coulthard K, Rayner CR, Paterson DL. Colistin: the re-emerging antibiotic for multidrug-resistant gram-negative bacterial infections. Lancet Infect Dis. 2006;6(9):589-601.

11. Lee CS, Doi Y. Therapy of infections due to Carbapenem-resistant gramnegative pathogens. Infect Chemother. 2014;46(3):149-64.

12. Cassini A, Hogberg LD, Plachouras D, Quattrocchi A, Hoxha A, Simonsen GS, Colomb-Cotinat M, Kretzschmar ME, Devleesschauwer B, Cecchini M, Ouakrim DA, Oliveira TC, Struelens MJ, Suetens C, Monnet DL. Attributable deaths and disability-adjusted life-years caused by infections with antibioticresistant bacteria in the EU and the European economic area in 2015: a population-level modelling analysis. Lancet Infect Dis. 2019;19(1):56-66.

13. Gandra S, Barter DM, Laxminarayan R. Economic burden of antibiotic resistance: how much do we really know? Clin Microbiol Infect. 2014; 20(10):973-80

14. David N. Gilbert, H.F.C., George M. Epiopoulos, Michael S. Saag, Andrew T. Pavia, Douglas Black, David O Freedman, Kami Kim, Brian S. Schwartz, The Sanford guide. To Antimicrobial therapy 2017. 47th ed. 2017.

15. Boucher HW, Talbot GH, Bradley JS, Edwards JE, Gilbert D, Rice LB, Scheld M, Spellberg B, Bartlett J. Bad bugs, no drugs: no ESKAPE! An update from the Infectious Diseases Society of America. Clin Infect Dis. 2009;48(1):1-12.

16. Livermore DM, Warner M, Mushtaq S, Doumith M, Zhang J, Woodford N. What remains against carbapenem-resistant Enterobacteriaceae? Evaluation of chloramphenicol, ciprofloxacin, colistin, fosfomycin, minocycline, nitrofurantoin, temocillin and tigecycline. Int J Antimicrob Agents. 2011;37(5):415-9.

17. Giamarellou H, Poulakou G. Multidrug-resistant gram-negative infections: what are the treatment options? Drugs. 2009;69(14):1879-901.

18. Izadpanah $\mathrm{M}$, Khalili $\mathrm{H}$. Antibiotic regimens for treatment of infections due to multidrug-resistant gram-negative pathogens: an evidence-based literature review. J Res Pharm Pract. 2015;4(3):105-14.

19. Poulikakos P, Tansarli GS, Falagas ME. Combination antibiotic treatment versus monotherapy for multidrug-resistant, extensively drug-resistant, and pandrug-resistant Acinetobacter infections: a systematic review. Eur J Clin Microbiol Infect Dis. 2014;33(10):1675-85.

20. Rafailidis PI, Falagas ME. Options for treating carbapenem-resistant Enterobacteriaceae. Curr Opin Infect Dis. 2014;27(6):479-83.

21. Magiorakos AP, Srinivasan A, Carey RB, Carmeli Y, Falagas ME, Giske CG, Harbarth S, Hindler JF, Kahlmeter G, Olsson-Liljequist B, Paterson DL, Rice LB, Stelling J, Struelens MJ, Vatopoulos A, Weber JT, Monnet DL. Multidrugresistant, extensively drug-resistant and pandrug-resistant bacteria: an international expert proposal for interim standard definitions for acquired resistance. Clin Microbiol Infect. 2012;18(3):268-81.

22. The National Heart, Lung, and Blood Institute. Guidance for Quality Assessment Tool for Systematic Reviews and Meta-Analyses. Available from: https://www.nhlbi.nih.gov/health-topics/study-quality-assessment-tools. Accessed 5 Aug 2018.

23. Moher D, Liberati A, Tetzlaff J, Altman DG. Preferred reporting items for systematic reviews and meta-analyses: the PRISMA statement. PLoS Med. 2009;6(7):e1000097.
24. Yoon YK, Kim JH, Sohn JW, Yang KS, Kim MJ. Role of piperacillin/tazobactam as a carbapenem-sparing antibiotic for treatment of acute pyelonephritis due to extended-spectrum beta-lactamase-producing Escherichia coli. Int J Antimicrob Agents. 2017;49(4):410-5.

25. Gutierrez-Gutierrez B, Bonomo RA, Carmeli Y, Paterson DL, Almirante B, Martinez-Martinez L, Oliver A, Calbo E, Pena C, Akova M, Pitout J, Origuen J, Pintado V, Garcia-Vazquez E, Gasch O, Hamprecht A, Prim N, Tumbarello M, Bou G, Viale P, Tacconelli E, Almela M, Perez F, Giamarellou H, Cisneros JM, Schwaber MJ, Venditti M, Lowman W, Bermejo J, Hsueh PR, Mora-Rillo M, Gracia-Ahulfinger I, Pascual A, Rodriguez-Bano J. Ertapenem for the treatment of bloodstream infections due to ESBL-producing Enterobacteriaceae: a multinational pre-registered cohort study. J Antimicrob Chemother. 2016; 71(6):1672-80.

26. Bassetti M, Righi E, Fasce R, Molinari MP, Rosso R, Di Biagio A, Mussap M, Pallavicini FB, Viscoli C. Efficacy of ertapenem in the treatment of early ventilator-associated pneumonia caused by extended-spectrum betalactamase-producing organisms in an intensive care unit. J Antimicrob Chemother. 2007;60(2):433-5.

27. Goethaert K, Van Looveren M, Lammens C, Jansens H, Baraniak A, Gniadkowski M, Van Herck K, Jorens PG, Demey HE, leven M, Bossaert L, Goossens $\mathrm{H}$. High-dose cefepime as an alternative treatment for infections caused by TEM-24 ESBL-producing Enterobacter aerogenes in severely-ill patients. Clin Microbiol Infect. 2006;12(1):56-62.

28. Kerneis S, Valade S, Geri G, Compain F, Lavollay M, Rostane H, Carbonnelle E, Mainardi JL. Cefoxitin as a carbapenem-sparing antibiotic for infections caused by extended-spectrum beta-lactamase-producing Escherichia coli and Klebsiella pneumoniae. Infect Dis (Lond). 2015;47(11):789-95.

29. Bin C, Hui W, Renyuan Z, Yongzhong N, Xiuli X, Yingchun X, Yuanjue Z, Minjun C. Outcome of cephalosporin treatment of bacteremia due to CTXM-type extended-spectrum beta-lactamase-producing Escherichia coli. Diagn Microbiol Infect Dis. 2006;56(4):351-7.

30. Tasbakan MI, Pullukcu H, Sipahi OR, Yamazhan T, Ulusoy S. Nitrofurantoin in the treatment of extended-spectrum beta-lactamase-producing Escherichia coli-related lower urinary tract infection. Int J Antimicrob Agents. 2012; 40(6):554-6.

31. Ipekci T, Seyman D, Berk H, Celik O. Clinical and bacteriological efficacy of amikacin in the treatment of lower urinary tract infection caused by extended-spectrum beta-lactamase-producing Escherichia coli or Klebsiella pneumoniae. J Infect Chemother. 2014;20(12):762-7.

32. Lee NY, Huang WH, Tsui KC, Hsueh PR, Ko WC. Carbapenem therapy for bacteremia due to extended-spectrum beta-lactamase-producing Escherichia coli or Klebsiella pneumoniae. Diagn Microbiol Infect Dis. 2011; 70(1):150-3.

33. Lee NY, Lee CC, Huang WH, Tsui KC, Hsueh PR, Ko WC. Carbapenem therapy for bacteremia due to extended-spectrum-beta-lactamaseproducing Escherichia coli or Klebsiella pneumoniae: implications of ertapenem susceptibility. Antimicrob Agents Chemother. 2012;56(6):2888-93.

34. Lee NY, Lee CC, Huang WH, Tsui KC, Hsueh PR, Ko WC. Cefepime therapy for monomicrobial bacteremia caused by cefepime-susceptible extendedspectrum beta-lactamase-producing Enterobacteriaceae: MIC matters. Clin Infect Dis. 2013;56(4):488-95.

35. Lo CL, Lee CC, Li CW, Li MC, Hsueh PR, Lee NY, Ko WC. Fluoroquinolone therapy for bloodstream infections caused by extended-spectrum betalactamase-producing Escherichia coli and Klebsiella pneumoniae. J Microbiol Immunol Infect. 2015;50(3):355-61.

36. Collins VL, Marchaim D, Pogue JM, Moshos J, Bheemreddy S, Sunkara B, Shallal A, Chugh N, Eiseler S, Bhargava P, Blunden C, Lephart PR, Memon BI, Hayakawa K, Abreu-Lanfranco O, Chopra T, Munoz-Price LS, Carmeli Y, Kaye KS. Efficacy of ertapenem for treatment of bloodstream infections caused by extended-spectrum-beta-lactamase-producing Enterobacteriaceae. Antimicrob Agents Chemother. 2012;56(4):2173-7.

37. Seo YB, Lee J, Kim YK, Lee SS, Lee JA, Kim HY, Uh Y, Kim HS, Song W. Randomized controlled trial of piperacillin-tazobactam, cefepime and ertapenem for the treatment of urinary tract infection caused by extendedspectrum beta-lactamase-producing Escherichia coli. BMC Infect Dis. 2017; 17(1):404.

38. Rattanaumpawan $P$, Werarak $P$, Jitmuang A, Kiratisin $P$, Thamlikitkul V. Efficacy and safety of de-escalation therapy to ertapenem for treatment of infections caused by extended-spectrum-beta-lactamase-producing Enterobacteriaceae: an open-label randomized controlled trial. BMC Infect Dis. 2017;17(1):183. 
39. Popejoy MW, Paterson DL, Cloutier D, Huntington JA, Miller B, Bliss CA, Steenbergen JN, Hershberger E, Umeh O, Kaye KS. Efficacy of ceftolozane/ tazobactam against urinary tract and intra-abdominal infections caused by ESBL-producing Escherichia coli and Klebsiella pneumoniae: a pooled analysis of phase 3 clinical trials. J Antimicrob Chemother. 2017;72(1):268-72.

40. Solomkin J, Hershberger E, Miller B, Popejoy M, Friedland I, Steenbergen J, Yoon M, Collins S, Yuan G, Barie PS, Eckmann C. Ceftolozane/Tazobactam plus metronidazole for complicated intra-abdominal infections in an era of multidrug resistance: results from a randomized, double-blind, phase 3 trial (ASPECT-CIAI). Clin Infect Dis. 2015;60(10):1462-71.

41. Carmeli Y, Armstrong J, Laud PJ, Newell P, Stone G, Wardman A, Gasink LB. Ceftazidime-avibactam or best available therapy in patients with ceftazidime-resistant Enterobacteriaceae and Pseudomonas aeruginosa complicated urinary tract infections or complicated intra-abdominal infections (REPRISE): a randomised, pathogen-directed, phase 3 study. Lancet Infect Dis. 2016;16(6):661-73.

42. Bassetti M, Repetto E, Righi E, Boni S, Diverio M, Molinari MP, Mussap M, Artioli S, Ansaldi F, Durando P, Orengo G, Bobbio Pallavicini F, Viscoli C. Colistin and rifampicin in the treatment of multidrug-resistant Acinetobacter baumannii infections. J Antimicrob Chemother. 2008;61(2):417-20.

43. Park SH, Choi SM, Chang YK, Lee DG, Cho SY, Lee HJ, Choi JH, Yoo JH. The efficacy of non-carbapenem antibiotics for the treatment of communityonset acute pyelonephritis due to extended-spectrum beta-lactamaseproducing Escherichia coli. J Antimicrob Chemother. 2014;69(10):2848-56.

44. Alvarez-Marin R, Lopez-Rojas R, Marquez JA, Gomez MJ, Molina J, Cisneros JM, Ortiz-Leyba C, Aznar J, Garnacho-Montero J, Pachon J. Colistin dosage without loading dose is efficacious when treating Carbapenem-resistant Acinetobacter baumannii ventilator-associated pneumonia caused by strains with high susceptibility to Colistin. PLoS One. 2016;11(12):e0168468.

45. Bremmer DN, Bauer KA, Pouch SM, Thomas K, Smith D, Goff DA, Pancholi P, Balada-Llasat JM. Correlation of checkerboard synergy testing with time-kill analysis and clinical outcomes of extensively drug-resistant Acinetobacter baumannii respiratory infections. Antimicrob Agents Chemother. 2016; 60(11):6892-5

46. Yilmaz GR, Guven T, Guner R, Kocak Tufan Z, Izdes S, Tasyaran MA, Acikgoz ZC. Colistin alone or combined with sulbactam or carbapenem against a. baumannii in ventilator-associated pneumonia. J Infect Dev Ctries. 2015;9(5):476-85.

47. Lopez-Cortes LE, Cisneros JM, Fernandez-Cuenca F, Bou G, Tomas M, Garnacho-Montero J, Pascual A, Martinez-Martinez L, Vila J, Pachon J, Rodriguez Bano J. Monotherapy versus combination therapy for sepsis due to multidrug-resistant Acinetobacter baumannii: analysis of a multicentre prospective cohort. J Antimicrob Chemother. 2014;69(11):3119-26.

48. Batirel A, Balkan II, Karabay O, Agalar C, Akalin S, Alici O, Alp E, Altay FA, Altin N, Arslan F, Aslan T, Bekiroglu N, Cesur S, Celik AD, Dogan M, Durdu B, Duygu F, Engin A, Engin DO, Gonen I, Guclu E, Guven T, Hatipoglu CA, Hosoglu S, Karahocagil MK, Kilic AU, Ormen B, Ozdemir D, Ozer S, Oztoprak N, Sezak N, Turhan V, Turker N, Yilmaz H. Comparison of colistin-carbapenem, colistin-sulbactam, and colistin plus other antibacterial agents for the treatment of extremely drug-resistant Acinetobacter baumannii bloodstream infections. Eur J Clin Microbiol Infect Dis. 2014;33(8):1311-22.

49. Vasilev K, Reshedko G, Orasan R, Sanchez M, Teras J, Babinchak T, Dukart G, Cooper A, Dartois N, Gandjini H, Orrico R, Ellis-Grosse E. A phase 3, openlabel, non-comparative study of tigecycline in the treatment of patients with selected serious infections due to resistant gram-negative organisms including Enterobacter species, Acinetobacter baumannii and Klebsiella pneumoniae. J Antimicrob Chemother. 2008;62(Suppl 1):i29-40.

50. Saballs M, Pujol M, Tubau F, Pena C, Montero A, Dominguez MA, Gudiol F, Ariza J. Rifampicin/imipenem combination in the treatment of carbapenemresistant Acinetobacter baumannii infections. J Antimicrob Chemother. 2006;58(3):697-700.

51. Ye JJ, Lin HS, Kuo AJ, Leu HS, Chiang PC, Huang CT, Lee MH. The clinical implication and prognostic predictors of tigecycline treatment for pneumonia involving multidrug-resistant Acinetobacter baumannii. J Inf Secur. 2011;63(5):351-61.

52. Kim WY, Moon JY, Huh JW, Choi SH, Lim CM, Koh Y, Chong YP, Hong SB. Comparable efficacy of Tigecycline versus Colistin therapy for multidrugresistant and extensively drug-resistant Acinetobacter baumannii pneumonia in critically ill patients. PLoS One. 2016;11(3):e0150642.

53. Goff DA, Bauer KA, Mangino JE. Bad bugs need old drugs: a stewardship program's evaluation of minocycline for multidrug-resistant Acinetobacter baumannii infections. Clin Infect Dis. 2014;59(Suppl 6):S381-7.
54. Cheng A, Chuang YC, Sun HY, Sheng WH, Yang CJ, Liao CH, Hsueh PR, Yang JL, Shen NJ, Wang JT, Hung CC, Chen YC, Chang SC. Excess mortality associated with Colistin-Tigecycline compared with Colistin-Carbapenem combination therapy for extensively drug-resistant Acinetobacter baumannii bacteremia: a multicenter prospective observational study. Crit Care Med. 2015;43(6):1194-204.

55. Kwon KH, Oh JY, Yoon YS, Jeong YJ, Kim KS, Shin SJ, Chung JW, Huh HJ, Chae SL, Park SY. Colistin treatment in carbapenem-resistant Acinetobacter baumannii pneumonia patients: incidence of nephrotoxicity and outcomes. Int J Antimicrob Agents. 2015;45(6):605-9.

56. Michalopoulos A, Fotakis D, Virtzili S, Vletsas C, Raftopoulou S, Mastora Z, Falagas ME. Aerosolized colistin as adjunctive treatment of ventilatorassociated pneumonia due to multidrug-resistant gram-negative bacteria: a prospective study. Respir Med. 2008;102(3):407-12.

57. Motaouakkil S, Charra B, Hachimi A, Nejmi H, Benslama A, Elmdaghri N, Belabbes $\mathrm{H}$, Benbachir M. Colistin and rifampicin in the treatment of nosocomial infections from multiresistant Acinetobacter baumannii. J Inf Secur. 2006;53(4):274-8.

58. Qin Y, Zhang J, Wu L, Zhang D, Fu L, Xue X. Comparison of the treatment efficacy between tigecycline plus high-dose cefoperazone-sulbactam and tigecycline monotherapy against ventilator-associated pneumonia caused by extensively drug-resistant Acinetobacter baumannii. Int J Clin Pharmacol Ther. 2018;56(3):120-9.

59. Chusri S, Sakarunchai I, Kositpantawong N, Panthuwong S, Santimaleeworagun W, Pattharachayakul S, Singkhamanan K, Doi Y. Outcomes of adjunctive therapy with intrathecal or intraventricular administration of colistin for postneurosurgical meningitis and ventriculitis due to carbapenem-resistant acinetobacter baumannii. Int J Antimicrob Agents. 2018;51(4):646-50.

60. Sirijatuphat $R$, Thamlikitkul V. Preliminary study of colistin versus colistin plus fosfomycin for treatment of carbapenem-resistant Acinetobacter baumannii infections. Antimicrob Agents Chemother. 2014;58(9):5598-601.

61. Aydemir H, Akduman D, Piskin N, Comert F, Horuz E, Terzi A, Kokturk F, Ornek T, Celebi G. Colistin vs. the combination of colistin and rifampicin for the treatment of carbapenem-resistant Acinetobacter baumannii ventilatorassociated pneumonia. Epidemiol Infect. 2013;141(6):1214-22.

62. Betrosian AP, Frantzeskaki F, Xanthaki A, Douzinas EE. Efficacy and safety of high-dose ampicillin/sulbactam vs. colistin as monotherapy for the treatment of multidrug resistant Acinetobacter baumannii ventilatorassociated pneumonia. J Inf Secur. 2008;56(6):432-6.

63. Betrosian AP, Frantzeskaki F, Xanthaki A, Georgiadis G. High-dose ampicillinsulbactam as an alternative treatment of late-onset VAP from multidrugresistant Acinetobacter baumannii. Scand J Infect Dis. 2007;39(1):38-43.

64. Durante-Mangoni E, Signoriello G, Andini R, Mattei A, De Cristoforo M, Murino P, Bassetti M, Malacarne P, Petrosillo N, Galdieri N, Mocavero P, Corcione A, Viscoli C, Zarrilli R, Gallo C, Utili R. Colistin and rifampicin compared with colistin alone for the treatment of serious infections due to extensively drug-resistant Acinetobacter baumannii: a multicenter, randomized clinical trial. Clin Infect Dis. 2013;57(3):349-58.

65. Kengkla K, Kongpakwattana K, Saokaew S, Apisarnthanarak A, Chaiyakunapruk N. Comparative efficacy and safety of treatment options for MDR and XDR Acinetobacter baumannii infections: a systematic review and network meta-analysis. J Antimicrob Chemother. 2018;73(1):22-32.

66. Sorli L, Luque S, Segura C, Campillo N, Montero M, Esteve E, Herrera S, Benito N, Alvarez-Lerma F, Grau S, Horcajada JP. Impact of colistin plasma levels on the clinical outcome of patients with infections caused by extremely drugresistant Pseudomonas aeruginosa. BMC Infect Dis. 2017;17(1):11.

67. Montero M, Horcajada JP, Sorli L, Alvarez-Lerma F, Grau S, Riu M, Sala M, Knobel $\mathrm{H}$. Effectiveness and safety of colistin for the treatment of multidrugresistant Pseudomonas aeruginosa infections. Infection. 2009;37(5):461-5.

68. Wright A, Hawkins $\mathrm{CH}$, Anggard EE, Harper DR. A controlled clinical trial of a therapeutic bacteriophage preparation in chronic otitis due to antibioticresistant Pseudomonas aeruginosa; a preliminary report of efficacy. Clin Otolaryngol. 2009;34(4):349-57.

69. Shirley M. Ceftazidime-Avibactam: a review in the treatment of serious gram-negative bacterial infections. Drugs. 2018;78(6):675-92.

70. Falagas ME, Rafailidis PI, Kasiakou SK, Hatzopoulou P, Michalopoulos A Effectiveness and nephrotoxicity of colistin monotherapy vs. colistinmeropenem combination therapy for multidrug-resistant gram-negative bacterial infections. Clin Microbiol Infect. 2006;12(12):1227-30.

\section{Publisher's Note}

Springer Nature remains neutral with regard to jurisdictional claims in published maps and institutional affiliations. 